\title{
Article
}

\section{DroneHack Journalism: Educating $\&$ Inspiring Journalists in the Capacities \& Possibilities of Unmanned Aerial Systems}

Heaton, Andrew, Mills, John and Ansell, Darren

Available at https://clok.uclan.ac.uk/21372/

Heaton, Andrew orcid iconORCID: 0000-0002-0523-1612, Mills, John orcid iconORCID: 0000-0002-4491-6796 and Ansell, Darren orcid iconORCID: 00000003-2818-3315 (2018) DroneHack Journalism: Educating \& Inspiring Journalists in the Capacities \& Possibilities of Unmanned Aerial Systems. 2018 AIAA Aerospace Sciences Meeting .

It is advisable to refer to the publisher's version if you intend to cite from the work. http://dx.doi.org/10.2514/6.2018-0180

For more information about UCLan's research in this area go to http://www.uclan.ac.uk/researchgroups/ and search for <name of research Group>.

For information about Research generally at UCLan please go to http://www.uclan.ac.uk/research/

All outputs in CLoK are protected by Intellectual Property Rights law, including Copyright law. Copyright, IPR and Moral Rights for the works on this site are retained by the individual authors and/or other copyright owners. Terms and conditions for use of this material are defined in the policies page. 


\title{
DroneHack Journalism: Educating \& Inspiring Journalists in the Capacities \& Possibilities of Unmanned Aerial Systems
}

\author{
Andrew E. Heaton*, John Mills ${ }^{\dagger}$ and Darren Ansell ${ }^{*}$ \\ University of Central Lancashire, Preston, Lancashire, UK
}

\begin{abstract}
The use of drones for journalism or newsgathering has been growing steadily over the past few years. The recent rise of Unmanned Aerial Vehicles (also known as drones) as consumer products, along with the increasing civilian applications being developed has sparked interest in people outside the aviation industry - including journalists. Drone journalism as a practice and discipline is still relatively new. However, they offer great journalistic potential. Current practice is based on visual media. Primarily this comprises photographs and video, but virtual reality and spherical (360) video is starting to be explored. However, other non-visual drone payloads offer great potential for sensor and data journalism. DroneHack has been developed as an event to bring those with technological skills and know-how together with those with real-world needs, in order to generate ideas and rapidly prototype the next generation of civilian drone applications. It also provides an opportunity to raise awareness of regulations around drones and their use. This paper describes the DroneHack Journalism event which took place in January 2017 in conjunction with journalism.co.uk and Trinity Mirror in Manchester, United Kingdom. The paper also explains what a DroneHack is, how it was developed as a format and the origins and influences as well as an overview of previous DroneHacks and concludes with some possible directions which future DroneHacks could take.
\end{abstract}

\section{Nomenclature}

$U A V=$ Unmanned Air Vehicle

\section{Introduction}

$\mathrm{T}$

$\mathrm{HE}$ recent rise of Unmanned Aerial Vehicles (UAVs) as consumer products, along with the increasing civilian (non-military) applications being developed has sparked a new interest in the general public. Von Hippel suggests the success user innovation can have during product development [1], and Rogers shows how they can impact upon diffusing innovation within a network [2]. Participatory design, co-design, and multidisciplinary collaborations are a working manifestation of these user-centric approaches, and commercial organizations adopt approaches such as open innovation [3] to fuel and accelerate innovation practices, as opposed to closed innovation practices that are designed to protect intellectual property and other commercial assets.

There is also a strong community of people who build their own UAVs growing from the ethos of the radiocontrolled aircraft communities, which are much in contrast with the large globally established aerospace companies. There are also those who can see the potential of UAVs but are unsure of how to engage with technology or the people who have the know-how.

DroneHack is a hackathon based around UAVs, their payloads, and the civilian applications and uses. DroneHack has been developed as an event to bring those with the technological skills and know-how (with regards to UAVs) together with those who have knowledge and experience in areas which could benefit from UAVs, to allow them innovate, generate ideas, and rapidly prototype the next generation of civilian UAVs. It also provides an opportunity to teach people about the current regulations around UAVs and their use.

\footnotetext{
${ }^{*}$ Research Associate, Civic Drone Centre, AIAA Member.

${ }^{\dagger}$ Lecturer and Researcher in Culture, Media and the Creative Industries, Media Innovation Studio.

* Space and Aerospace Engineering Lead, School of Engineering.
} 
Hackathons as a method of rapid prototyping have been present in a number of fields for a number of decades, with named hacks being identified in 1999 at the JavaOne conference and Sun Microsystems and OpenBSD use at an event in Calgary. However, the concept of rapid development over a limited time span no doubt has a long lineage. The unique element is evolving this process into an 'event' that is open to members of the public to participate in. Hacks are now a regular feature across a range of industries, ranging from Nasa's Space Apps Challenge ${ }^{\S}$ to marketing and advertising sessions for the news and media sector to community groups and social innovation.

According to Briscoe and Mulligan [4] although hackathons are diverse they classified into two groups tech-centric (hackathons focused on a specific technology or application) or focus-centric (hackathons focused a social issue or business objective). DroneHacks fall into the latter, designed to foster rapid innovation and prototyping of UAV applications to solve real-world problems, by bringing subject matter experts (e.g., humanitarians, rescue workers, journalists) together with technologists, programmers, and engineers.

Participants arrive as individuals and then form teams, facilitated by the University of Central Lancashire's Civic Drone Centre to ensure a mix of technical skills and ideas. Provided with all the parts and equipment they need build a UAV, as well as, a selection of single-board computers and a plethora of sensors, servos, and output devices to build payloads with.

Teams then have to work hard to complete the task in the short amount of time allowed, competing against each other for a chance to win the 3D-printed 'Golden Drone' trophy, a light-hearted mechanism that sought to reward the winning team. This light-hearted and open approach was a core element of the sessions, which sought to invite people into an informal and approachable session that was, amongst other things, 'fun'. Teams are not expected to produce the final product but explore their ideas and what is possible (even if they have to use less capable sensors as proxies) to end up with a proof-of-concept demonstrator.

\section{A. DroneHack Development}

DroneHack utilizes affordable processing devices such as Arduino, Raspberry Pi and a range of other cheap and accessible computing hardware (e.g., sensors, liquid-crystal display screens). These falling costs have reduced barriers to entry in relation to user-led cyber-physical innovation. These single-board computers and hardware can form the basis of a payload for a UAV which can be developed quickly. Also, the recent popularity of UAVs as consumer products and toys has also reduced the price and increased the availability of 'ready to fly' UAVs and build kits.

While there have been many UAV building events organized across the world DroneHack capitalizes on these innovations in computing and unmanned aviation in the form of a hackathon to produce a proof-of-concept prototype to address a need - rather than simply an opportunity to build a UAV.

\section{Intentions}

The following principles were used when creating DroneHack, these are in part derived from the general principals observed by Briscoe and Mulligan [4]:

- Civilian uses;

- Themed hacks;

- Free to the participants;

- Bring together people with application domain knowledge and people with technical skills;

- UAVs must be designed, built, and flown during the DroneHack;

- $\quad \&$ the UAV must have a purpose which fits with the theme;

- A combination of physical and software hacking;

- All equipment, tools, and parts needed will be provided (no need for the participants to bring anything);

- Competitive element.

2. Theme

Theming the DroneHack offers links to real word issues that individuals or organizations face. A balance must be struck when choosing a theme for a DroneHack that balances between focusing the efforts of the teams to achieve something during the event and not constraining them too much. The themes for the first two DroneHacks were both 'humanitarian' and the next two on 'journalism', but the format can easily be applied to other themes such as 'agriculture' or 'delivery'. Themes need to be relatively wide-ranging, but the key 'problem' that participants are vital to team engagement.

\footnotetext{
$\S$ https://spaceappschallenge.org/
} 


\section{Target Audience}

One of the intentions is to bring together people with domain knowledge (in the chosen theme) - who may have little to no experience or knowledge relating to UAVs, computing or relating technology - and those with the technical skills - who may have little or no knowledge of what problems are faced on the ground in the real world. Due to this the target audience for a DroneHack it quite large and has a wide range of competencies in technological skill levels. This means that the events need to allow activities for all skill levels so that beginners can contribute without being overwhelmed and experienced people can use their skills to the fullest.

Civic Drone Centre staff, dubbed 'Drone Doctors', were there throughout the events to provide support and troubleshooting on technical snags as well as to facilitate the event and keep the teams on track. Working with people with little or no experience with UAVs - both in terms of flying and the technology. This was a key element for allowing the sessions to be as inclusive as possible. Participants did not need any prior aviation, engineering, software or other forms of technical knowledge, simply ideas. For those without flying experience opportunities were built into the events to allow people to practice their flying. This included a UAV flight similar so people could get use the controls before they had even built their UAV.

\section{Safety}

Safety is a priority in any DroneHack. As UAV are being built and tested there is an inherent risk that something could go wrong, to control and mitigate these risks University of Central Lancashire's risk assessment procedure was followed. Some control methods implemented were: use of personal protective equipment, controls on who and how UAVs could be handled, segregation of people and the flying area. Additionally, all flights were conducted indoors.

\section{B. Generic Flow of a DroneHack Event}

Figure 1 shows the generic process of planning a running a DroneHack event. The process can be divided into two main phases the event itself and the pre-event planning phase. The pre-event phase is dedicated to planning and promoting the DroneHack. Also in this phase, the equipment needed can be tailored to the theme. The second phase is the event itself. The main portions of the event are the designing, building and flight testing of the UAVs, which will take up the majority of the event time. This flow was the format DroneHack Journalism took.

\section{Previous DroneHacks}

\section{A. DroneHack}

The first DroneHack lasted one day and three teams were formed. The winning team's drone was equipped with cameras and sensors to identify a drowning person, tweet their GPS location, and deploy a floatation device for the victim to cling to whilst awaiting a manned rescue boat.

The second team's drone was one designed be used by humanitarian organizations in Syria. Their drone was designed to fly around an area where a bomb had exploded testing the air for chemicals to ascertain whether or not it was safe or not for humanitarian workers to enter. The third team (which consisted one person) did not engage with the theme or competition elements and simply enjoyed building a UAV.

\section{B. DroneHack 2.0}

DroneHack 2.0 took place over two days. The decision was made to increase the even length to allow more time for teams to develop/iterate their ideas. However, it was observed that instead of iterating ideas the teams took longer building their UAVs and payloads - achieving a similar level of maturity of design as in the first DroneHack.

Two teams were formed. The winning team built and flew, a drone equipped with a payload for detecting the infrared beacons on lifejackets to aid search and rescue efforts at sea. The second team created a drone which acted as a wifi hotspot to provide a basic information service for when communications infrastructure is damaged post a natural disaster.

\section{DroneHack Vienna}

DroneHack Vienna was cut down version of the DroneHack format to fit into a two-hour workshop at Digital Media Europe 2016 in Vienna, Austria**. This DroneHack only involved presentations and ideation of the payload using sensors only, i.e., there was no coding. These sensors were attached to drone airframes without any of the electronics. The winning team's UA V was designed to monitor bushfires in Australia - adding thermal imaging and sensor data to the storytelling mix.

\footnotetext{
** https://events.wan-ifra.org/events/digital-media-europe-2016/
} 


\section{Pre-Event}

- DroneHack Theme Selection

- Equipment Selection (UAVs, sensors, etc.)

- Agenda Creation

- Speaker Selection

- Ticketing \& Promotion

- Detailed Planning \& Preperation

- Confirmation of Attendees

- Send out Event Information

\section{Event}

-Welcome

- Presentations

- Team Forming

- Ideation \& Design

- Kit Introduction

- Build Time (UAV \& Payload)

- Lunch

- Presentations

- Build Time

- Flight Test \& Team Presentations 


\section{Journalist Use \& Potential of Drones}

A number of reports, blog posts and journal articles have marked out the potential for drone journalism to develop as a field or area of expertise, and this positivity is still permeating industry discourse and trend predictions. Many commentators focus on how drone operations can be directed and utilized by the news media. Nebraska Lincoln's Drone Journalism Lab, founded by Matt Waite, suggests that drones are 'an ideal platform' for journalism - combining high definition recording devices with airborne potential [5]. It is suggested that the general populous will increasingly see the opportunities they present and move beyond some of the negative associations that military use has and also create more editorial potential than 'paparazzi' style shots of the rich and famous [6].

Reuters Institute has also highlighted drone journalism as an area of interest, and potential expansion thanks to the growing affordability of drone platforms [7]. They suggest that “... for major news organizations, faced with increased budgetary pressures, the appeal is immediate; why operate a fleet of multi-million dollar news helicopters when many of the dull, dirty and dangerous tasks could potentially be done buy a $£ 20,000$ or even a $£ 500$ drone?”. Clarke [8] echoes this potential, but develops some of the journalistic considerations. He suggests media organizations could, thanks to drone technology, create the capacity to capture multiple aerial feeds, continuous monitoring, automated monitoring and multi-location coordination. However, Clarke does temper some of these opportunities through drawing a stark contrast between drone journalism in the public interest and that which is of interest to the public. Using the term 'voyeurnalism', he suggests "helicopters and fixed-wing aircraft have been too expensive for any significant use of paparazzi whereas drone are creating a 'Paparazzi Aloft' problem.

Drones enable physical barriers in the line of sight to be overcome, and imagery to be captured. Vertical and angled shots can be achieved. Continuous monitoring can be undertaken of bottleneck locations such as the target's front door". Figure two visualizes the potential Clarke sees in using UAVs to overcome line-of-sight-to-story-subject. This potential can be seen editorially in Channel 4's Drones in Forbidden Zones [9], Hidden Britten by Drone [10].

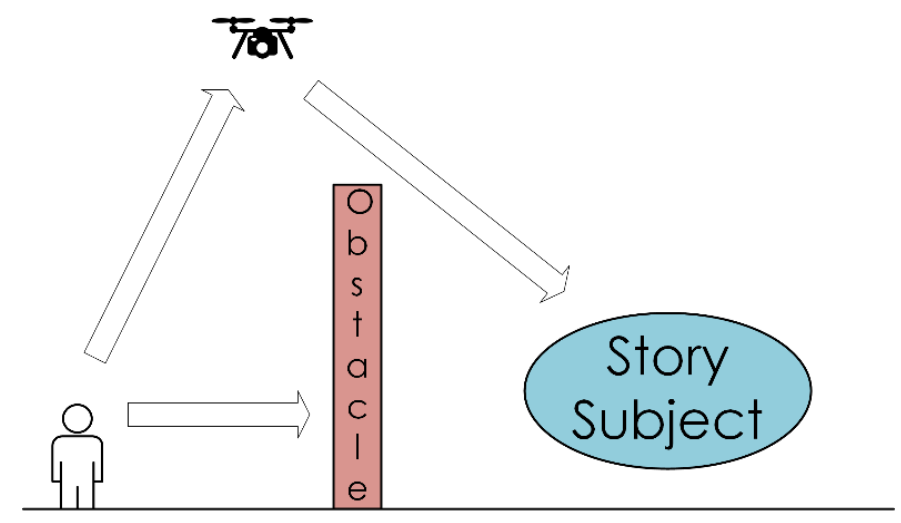

Figure 2: The ability of a drone to extend journalistic vision. ${ }^{\dagger \dagger}$

\section{V.II. DroneHack Journalism}

DroneHack Journalism is a direct evolution of the preceding three DroneHacks and designed to inspire journalists to use UAVs to their full potential. The event was designed to expose journalists (print, broadcast and multimedia) to UAVs and the potential they offer - beyond the standard UAV aerial photography and video - and also to include the idea of using sensors mounted on UAVs for storytelling and journalism.

\section{A. Partner Organizations}

Trinity Mirror is one of the largest newspaper publishers in the United Kingdom. They publish over one hundred and fifty titles. They include national newspapers, such as the Daily Mirror ${ }^{\dagger}$, as well as regional publications, such as the Manchester Evening News $\$$.

\footnotetext{
${ }^{\dagger}$ Drone icon courtesy of Joris Hoogendoorn, available at: https://thenounproject.com/term/drone/118021/

\$t http://www.mirror.co.uk/

$\S \S \mathrm{http}: / / \mathrm{www}$. manchestereveningnews.co.uk/
} 
Journalism.co.uk is a website aimed at professional journalists in the UK. It offers industry news, training, and job postings.

\section{B. Pre-Event Planning}

\section{Location}

The location chosen for the event was the SHARP Project in Manchester ${ }^{* * *}$. This location was chosen because it had a large open cafeteria where the lectures and hacking could take place, as well as having TV/film studio space which could be controlled when flying UAVs. In addition to this Manchester has good transport links, and vibrant creative industries and journalism community.

\section{Equipment}

The following equipment prepared in advance was made available to the teams on the day:

- A quadcopter drone kit - airframe, flight controller, transmitter \& receiver, motors, electronic speed controllers,

- Raspberry Pi

- $G^{-}$rove ${ }^{\dagger \dagger}$ shield for Raspberry Pi.

- Several Grove sensors, actuator, and displays. These were different for each team, see the appendix for an example list.

- A laptop.

- Power \& connection cables.

- Pens, markers, and paper.

- Instruction manuals \& quick start guides.

\section{Ticketing \& Promotion}

The event tickets were free and managed via an online event ticketing site. First refusal was given to partner organizations before tickets were made available to the public. The event was advertised on the ticketing platform and social media. A waiting list was also established, and participants were asked to reconfirm their attendance prior to the event and tickets of those who could no longer attend given to those on the waiting list.

Also, when completing the application form the participants were asked to provide some basic information on their jobs and what experience they had with UAVs and programming. This information was used by the organizers to better understand the type of people attending the event and thus tailor the content and support to suit their level of experience.

\section{The Event}

\section{Presentations}

Several presentations were given during the day, the first two were given by UCLan staff. The first being a welcome to DroneHack, the agenda for the day, and a general introduction to drone journalism. The second was covering the basics of UAV regulations in the UK and how to get permission for commercial operations.

The rest of the presentations were given by guest speakers. These were on: cinema journalism and how it related to drone journalism was given by David Dunkley Gyimah $\$$; drone journalism in Kenya by Dickens Olewe ${ }^{\S \S}$; being an independent journalism technologist by Ben Kreimer ${ }^{* * * * *}$; SkyTango as drone footage marketplace by Steven

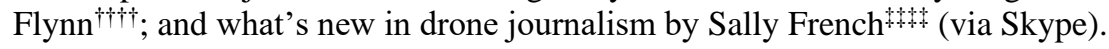

\footnotetext{
*** http://www.thesharpproject.co.uk/

tT Grove is a modular system with standardised connections for prototyping - http://wiki.seeed.cc/Grove_System/

t+ $\mathrm{http}: / / \mathrm{www}$.daviddunkleygyimah.com/

$\S \S \mathrm{http}: / /$ www.africanskycam.com/

${ }^{* * * * *}$ http://benkreimer.com/

$\dagger+1$ https://skytango.com/

$\mathrm{ttm} \mathrm{http}: / /$ thedronegirl.com/
} 


\section{Drone Displays}

There were three displays during the event and participants were free to visit them whenever they wanted. The first was a drone flight simulator. The second was the drone and equipment Ben Kreimer uses to create and display $3 \mathrm{D}$ reconstructions. The third was a drone equipped with a payload which could track where people have been using the list of wifi networks in their cellular phone - to highlight the privacy issues associated with drones.

\section{Team Ideas}

Three teams formed on the day. The winning team's idea was to augment drone video footage with sensor data (augmented reality) to tell a story. The second abandoned the use of drones altogether. They opted to create pollution monitoring devices attached to helium balloons which could be carried around by people. The third team created a personal drone that would capture an individual's day via multimedia content and sensor data, thus providing a media capture experience that was unique to the individual.

\section{Social Media Use}

During the event, both the staff and participants were encouraged to post about the DroneHack to their social media accounts. Tweets from the day using \#dronehack were compiled using Storify by the SHARP Project ${ }^{\S \S \S}$.

\section{Discussion \& Conclusion}

Looking at the original intention of DroneHacks Journalism and what was achieved on the day, it can be considered successful. It brought together people of different backgrounds and skill levels to design, build, and fly UAV prototypes which address a real word issue over a short period of time. It also created space for other discussions that led onto separate collaborations between participants to take place beyond the day itself.

However, there are limitations to DroneHacks. First, is the ethos being open to all, regardless of experience. This limits the complexity of an idea which can be realised in the time. Second, the imposed time limit. This time limit constrains innovative thinking. Third, choice of equipment - both in terms of drones and sensors. The choice to use a quadcopter frame was twofold: it is the most common type of UAV on the consumer market and the ability to hover (making it easier for a new pilot to control). But this limited the teams thinking to quadcopters, and what sort of payloads they can carry. Fixed-wing and less conventional aircraft designs are omitted.

There are several options for continuing DroneHack events:

1. Continue DroneHack in their current format, as outlined in Fig. 1 with the same equipment;

2. Continue to develop variations of the DroneHack format, e.g., focus on the payload only, use a fixedwing platform, a software-only DroneHack focused on, or run an event for experienced people; \&

3. Develop guidance and support for other groups (external to the University of Central Lancashire) so that they can organize and run their own DroneHacks independently.

The above options are not mutually exclusive and the third will greatly increase the number of variation possible.

Finally, research into the DroneHack methodology could be conducted. Several aspects could be explored, for example, comparison to other hackathon and hack methodologies could be performed, how it relates to hacktivism, how many people take the ideas forward post the event, and how the different skill levels of participants effects engagement and role selection.

\section{Appendix}

The list below is that of the sensors, actuators and displays made available to Team 1.

- Temp \& Humidity Sensor

$\circ$ This sensor simultaneously measures ambient temperature and humidity. On a drone it could be used to provide more accurate local weather reports.

- Blue - http://wiki.seeed.cc/Grove-TemperatureAndHumidity_Sensor/

○ White - http://wiki.seeed.cc/Grove-Temperature_and_Humidity_Sensor_Pro/

- UV Sensor

- The UV sensor behaves similarly to the light sensor but it only responds to ultra-violet light.

○ http://wiki.seeed.cc/Grove-UV_Sensor/

- $\quad$ Blue LED

$\S \S \S$ https://storify.com/sharpproject/dronehack-at-the-sharp-

project?utm_source=embed\&utm_medium=publisher\&utm_campaign=embed-header 
- Green LED

- Light-emitting diode (LED) - a two-lead semiconductor light source. Can be used to indicate something.

○ http://wiki.seeed.cc/Grove-LED_Socket_Kit/

○ Light-emitting diode (LED) - a two-lead semiconductor light source. Can be used to indicate something.

○ http://wiki.seeed.cc/Grove-LED_Socket_Kit/

- 4 Digit Display

- The red LED display can up to 4 alpha-numeric values. It could be used to count, display sensor values, or display time.

○ http://wiki.seeed.cc/Grove-4-Digit_Display/

- Ultrasonic Range Finder

- This sensor uses a beam of ultrasound to measure distance. This sensor is often used for collision avoidance on drones and other mobile robots.

- http://wiki.seeed.cc/Grove-Ultrasonic_Ranger/

- Magnet Switch

- This sensor is a double-ended type and may be actuated with an electromagnet, a permanent magnet or a combination of both.

○ http://wiki.seeed.cc/Grove-Magnetic_Switch/

- Gesture Sensor

- This sensor can recognize 9 basic gestures. Up, Down, Left, Right, Forward, Backward, Clockwise, Count Clockwise, Wave.

○ http://wiki.seeed.cc/Grove-Gesture_v1.0/

- Sound Sensor

- This sensor does not record sound but measures the surrounding noise level. It could be used to listen for survivors after an earthquake or building collapse.

○ http://wiki.seeed.cc/Grove-Sound_Sensor/

- $\quad$ LCD RGB Backlight Display

$\circ$ The LCD is a liquid crystal display capable of displaying text. The screen includes a backlight allowing it to be used in all light conditions.

○ http://wiki.seeed.cc/Grove-LCD_RGB_Backlight/

- Recorder

- Unlike the sound sensor this sensor digitally records sound and can replay the recording at a later date.

- Speaker

○ http://wiki.seeed.cc/Grove_Recorder/

- The speaker is a module which consists of power amplification and voice outputs.

VIII. Acknowledgments

The authors would like to thank both journalism.co.uk and Trinity Mirror for their input and help in organizing and running the event. Thanks also go to The SHARP Project for their use as a venue and the presenters for sharing their knowledge and experience on the day.

\section{References}

[1] Von Hippel, Eric. The Sources of Innovation. Oxford University Press, 1988

[2] Rogers, E. M., Diffusion of innovations, Simon and Schuster, 2010.

[3] Chesbrough, H. W., "Open innovation: The new imperative for creating and profiting from technology," Harvard Business Press, 2006.

[4] Briscoe, G. \& Mulligan, C., "Digital innovation: The hackathon phenomenon," Creativeworks London Working Paper No.6, 2014.

[5] "Drone journalism lab - about the lab," URL: http://www.dronejournalismlab.org/about [retrieved 30 November 2017]. 
[6] Waite, M., "Journalism with Flying Robots," XRDS: Crossroads, the ACM Magazine for Students, 20(3), 28-31, 2014.

[7] Goldberg, D., Corcoran, M., \& Picard, G., "Remotely piloted aircraft systems \& journalism. Opportunities and challenges of drones in news gathering," [Report], Reuters Institute for the Study of Journalism, 2013.

[8] Clarke, R., "Understanding the drone epidemic," Computer Law and Security Review, 30(3), 230-246. doi:10.1016/j.clsr.2014.03.002, 2014.

[9] Georgeson, L., (Director), "Drones in forbidden zones," [Video] Little Dot Studios Ltd, 2015.

[10] Myerscough, J. and O'Shea, E. (Directors), "Hidden Britain by drone," [TV Show] Windfall Films, 2016. 